\title{
Can we predict which patients with plantar heel pain are more likely to benefit from insoles? A secondary exploratory analysis of a randomized controlled trial
}

\author{
N. Rasenberg, L. J. M. Dijkgraaf, P. J. Bindels, S. M. Bierma-Zeinstra and M. van Middelkoop*
}

\begin{abstract}
Background: Plantar heel pain (PHP) is a common cause of foot complaints, for which treatment with custommade insoles is frequently applied. So far few studies have investigated patient characteristics that predict response to these treatments. The aim of this secondary exploratory analysis was twofold; firstly, to identify patient characteristics that predict prognosis in patients with PHP treated with insoles, and secondly to identify characteristics that might interact with treatment with insoles.

Methods: Data from a randomized trial in which participants received either custom insoles $(N=70)$ or sham insoles $(N=69)$ were used. At baseline, information was collected on demographics, foot symptoms, foot and ankle range of motion, navicular drop, presence of neuropathic pain, physical activity and other illnesses in the last 12 months. The primary outcome of this study was the Foot Function Index score (FFI) at 26 weeks. Multivariable linear regression models were generated to identify patients characteristics that predict the outcome for each type of intervention (i.e. insoles and GP-led usual care).

Results: We found two variables associated with a better function score at 26 weeks in patients treated with insoles, female sex ( $\beta-9.5995 \% \mathrm{Cl}-17.87 ;-1.31)$ and a lower FFI score at baseline ( $30.5695 \% \mathrm{Cl} 0.30 ; 0.82)$. Explorative analyses in patients treated with insoles showed no significant interaction effects between the type of insole (custom-made versus sham) and any of the potential predictive factors.
\end{abstract}

Conclusion: When communicating about the effect of insoles for PHP clinicians should take sex and the amount of pain and disability at first presentation into account. Women and people with better foot function scores at baseline (according to FFl) might respond better to treatment with insoles in terms of foot function.

Trial registration: Trial registration: NTR5346.

Keywords: Plantar heel pain, Insoles, Prognosis, Patient characteristics

\section{Background}

Plantar heel pain (PHP), is most commonly defined as pain located at the anteromedial part of the plantar heel during weight-bearing when plantar fascia pathology has

\footnotetext{
* Correspondence: m.vanmiddelkoop@erasmusmc.nl

Department of General Practice, Erasmus MC, University Medical Center, PO Box 2040, 3000, CA, Rotterdam, The Netherlands
}

not been confirmed by imaging $[1,2]$. The incidence in the Dutch general practice is estimated to be 3.83 per 1.000 person-years, where the average general practitioner (GP) sees approximately 8 new cases each year [3]. Several risk factors for developing PHP have been identified in literature, including a high BMI, limited ankle dorsiflexion, being a runner, work-related weight-

C C The Author(s). 2022 Open Access This article is licensed under a Creative Commons Attribution 4.0 International License, which permits use, sharing, adaptation, distribution and reproduction in any medium or format, as long as you give appropriate credit to the original author(s) and the source, provide a link to the Creative Commons licence, and indicate if changes were made. The images or other third party material in this article are included in the article's Creative Commons licence, unless indicated otherwise in a credit line to the material. If material is not included in the article's Creative Commons licence and your intended use is not permitted by statutory regulation or exceeds the permitted use, you will need to obtain permission directly from the copyright holder. To view a copy of this licence, visit http://creativecommons.org/licenses/by/4.0/. The Creative Commons Public Domain Dedication waiver (http://creativecommons.org/publicdomain/zero/1.0/) applies to the data made available in this article, unless otherwise stated in a credit line to the data. 
bearing activities and being female [4-8]. The long term prognosis of PHP is unknown, as the duration of complaints of PHP varies greatly among studies $[1,8,9]$. PHPhas a significant negative impact on quality of life (both in terms of general and foot specific health) [10]. Most reported complaints are difficulties carrying out work-related activities and sports activities [11]. Treatment strategies vary greatly among GPs and multiple interventions are often applied in patients with PHP during the course of their complaints [3]. Of the many treatments options available, orthotic devices, such as insoles, are one of the most commonly prescribed interventions $[3,12]$. Though, evidence on the effectiveness of insoles in patients with PHP is conflicting [13-15]. With Whittaker et al. finding: "moderate-quality evidence that foot orthoses are effective at reducing pain in the medium term" [14]. And Rasenberg et al. concluding: "Foot orthoses are not superior for improving pain and function compared with sham or other conservative treatment in patients with PHP." [16] A recent best practice guideline based on systematic review of literature and clinical expert reasoning found: "good agreement to 'step care' using custom foot orthoses for general pain in the short term." [17].

Little is known about factors that might predict recovery or response to treatment with insoles in patients with PHP. Whittaker et al. recently found: "People with plantar heel pain who use foot orthoses experience reduced foot pain if they have greater ankle dorsiflexion and lower BMI, while they experience improved foot function if they have lower fear-avoidance beliefs and lower BMI." [18] Whereas, Wu et al. identified several physical measures that if present increased the rate of positive outcome (in terms of pain function or recovery) in patients that received custom foot orthosis for PHP [19]. Though, more studies focusing on predicting response to treatment using data from high-quality studies are needed. A recent randomized controlled trial from our group found that GPled usual care seemed to be slightly more beneficial than treatment with custom-made insoles and found no differences between custom-made insoles and sham insoles [15]. However, some patients did report an improvement after receiving insoles, while others did not. In this trial no differences were found between custom-made insoles and sham insoles and blinding between these two groups was successful [15]. This means that the context for patients in these two groups was identical and that the data from these patients is suitable to assess the prognosis of PHP in patients treated with insoles as an overall group. Therefore, the aim of this secondary exploratory analysis was twofold; firstly, to identify patients characteristics that predict the long-term complaints of patients with PHP treated with insoles, and secondly to identify characteristics that might interact with insole treatment response.

\section{Methods}

\section{Population}

For this secondary analysis, data from a previously published randomized trial investigating the effectiveness of treatment with custom-made insoles in patients with PHP were used [15]. PHP was characterised as pain at the medial hind foot, reproducible on palpation. Inclusion criteria for PHP were: age between 18 and 65 years, minimal pain duration of 2 weeks and presentation with PHP, characterised as pain at the medial hind foot, to a GP or sports physician. Exclusion criteria were recurrent complaints of PHP for more than 2 years, complaints caused by trauma, earlier treatment for PHP by a podiatrist or with insoles, suspected (by the GP or sports physician) (osteo) arthritis in the subtalar or talonavicular joint, suspected tarsal tunnel syndrome, suspected stress fractures, infections or tumours in the painful foot, presence of systemic diseases (such as ankylosing spondylitis, psoriasis or multiple sclerosis) and insufficient understanding of the Dutch language. The trial adhered to the principles of the Declaration of Helsinki and the medical ethical committee of the Erasmus Medical Centre has approved the study (MEC: 2015-253) and was prospectively registered at the Dutch Trial Registration (NTR5346) [20]. Patients between ages 18-65 years, that presented themselves at their GP with PHP and with a minimum of 2 weeks of complaints were eligible for this trial. A total of 185 patients were included, after informed consent was received. For the current study, only participants who received an insole treatment were included.

\section{Interventions}

Patients allocated to the custom-made insole group were referred to a podiatrist and randomly allocated to receive either a custom-made insole or a sham insole. The custom-made insole was produced according to the standard practice of their podiatrist $(n=70)$. The purpose of the custom-made insole was to influence the biomechanical process to reduce traction on the plan$\operatorname{tar}$ aponeurosis and to reduce ground reaction force below the tuber calcaneus. The sham insoles were produced according to a standardized procedure, all by the same podiatrist $(n=69)$. The sham insoles were designed to provide as little mechanical effect as possible, while having a visual effect similar to that of a custom insole. The patients were blinded to the type of insole they received. All patients received an information booklet containing general information on PHP including stretching and strengthening exercises targeted at PHP $[4,16]$. Further details of the STAP study, and on the procedures mentioned here, are described elsewhere $[13,15]$. 


\section{Measurements}

At baseline all participants filled in a questionnaire containing questions regarding demographics: age, sex, weight and length (to calculate body mass index (BMI)); general health status: musculoskeletal pain other than in the foot, self-reported illnesses in the last 12 months; foot complaints: affected side (right, left or bilateral), duration of complaints, pain severity (11-point numerical rating scale (NRS), including first step pain, pain in rest and during activity), neuropathic aspect of the pain according to the Doleur Neuropathique 4 (DN4 (range, 0-10)) [21], the Foot Function Index (FFI (range, 0100), higher score indicates more disability/worse function) [22] and questions regarding lifestyle factors: physical activity (Short QUestionnaire to ASsess Health enhancing physical activity (SQUASH) questionnaire) [23] and standing work for a prolonged time (4-point Likert scale). For further analysis, participants, who indicated 'bilateral' as the affected side $(N=32)$, were randomly assigned to either 'left' or 'right'.

Patients that were referred to a podiatrist underwent a standardized physical examination, including the range of motion in the tarsometarsal joint and the first metatarsophalangeal joint (MTP-I) as measured with a goniometer (number of degrees), the navicular drop test (millimeters) [24] and the posture of the foot using the standardized foot posture index (FPI) of both feet [25]. The podiatrist was blinded for participant allocation while performing these measurements.

At 12 and at 26 weeks participants received questionnaires containing questions on foot function (FFI), selfreported recovery (7-point Likert scale) and pain severity in rest, during activity and first step pain (11-point NRS).

\section{Outcomes and variable selection}

The FFI total score at 26 weeks was used as the primary outcome. Secondary outcomes included: the number of patients that reached a minimal important improvement in their total FFI score (an improvement of at least 6.5), the number of patients that considered themselves recovered, the first step pain according to a 11 point NRS and the number of patients that reached a minimal important improvement in their first step pain (an improvement of at least 1.9.) [26, 27] Potential prognostic variables were selected based on supposed clinical relevance and existing literature. The following variables were considered: age, sex, BMI, upper ankle dorsiflexion range of motion in the affected foot, MTP1 dorsiflexion range of motion in the affected foot, navicular drop (ND) in the affected foot, neuropathic pain score in the affected foot (DN4), having bilateral pain, degree of physical activity, reporting other illnesses in the last 12 months, duration of symptoms, FFI scores at baseline and the FPI [22, 25, 28-30]. The FPI was divided into three groups. According to the criteria by Redmond et al. 2006: in patients over 60 years of age, a score between 1 and 8 was considered neutral foot posture, a score below 1 was considered supinated foot posture and a score above 8 was considered pronated foot posture. In patients between 18 and 60 years, a score between 1 and 7 was considered normal foot posture, a score below 1 was considered supinated foot posture and a score above 7 was considered pronated foot posture [25].

\section{Statistical analysis}

If missing values were completely random and the underlying values were normally distributed, they were imputed and if applicable, the minimum and maximum values were assigned as constraints by the researchers. MTP1 joint dorsiflexion $(N=12$; range, $0-\infty)$, upper ankle joint dorsiflexion ( $\mathrm{N}=12$; range, $0-90)$, foot posture index $(N=8$; range, -12 to12) and FFI total score at 26 weeks (without subscales) $(N=16$; range, $0-100)$ were imputed. 50 Imputations and 20 iterations using fully conditional specification (Markov Chain Monte Carlo (MCMC)) were used [31].

Descriptive statistics were used to describe the selected outcome variables and to calculate to number of patients that reached an minimal important difference. All variables were tested for normality of residuals using P-P plots and homoscedasticity was visually checked by inspection of scatterplots of residuals. All variables were checked for a linear relationship with the outcome variable. Multicollinearity was checked using bivariate correlations. First, univariate analyses were performed using linear regression to test the association between each of the potential prognostic factors as described above and the outcomes ((i.e. FFI total score, recovery and first step pain respectively), in patients treated with insoles. The data was checked for outliers, and in case of impossible values, the value was removed. Thereafter, multivariable linear regression analyses with an ENTER model were performed to test the association between the potential prognostic factors as described above and each of the outcomes (i.e. FFI total score, recovery and first step pain respectively) after 26 weeks of follow-up in patients treated with insoles.

Secondly variables with a significant association with the FFI score at 26 weeks in patients treated with insoles were tested for interaction effects using linear regression, with the allocated treatment in patients treated with custom-made insoles versus sham. All analyses were performed using SPSS v25.0.

\section{Results}

Baseline characteristics of the 139 included participants (sham insole group $N=69$, custom insole group $N=70$ ) 
are presented in Table 1 . Table 2 shows the outcomes of participants at 12 and 26 weeks follow-up. Mean total FFI score at baseline was 48.7 for the total population indicating moderate foot function levels. FFI scores improved during follow up ( 26 weeks) on average with 24 points. At 26 weeks, $79.1 \%$ of all participants reached FFI total score MID (an improvement of at least 6.5 points). Women reported higher symptom and lower foot function scores than men at baseline .

The univariate analyses in patients treated with insoles (Table 3) showed that having unilateral pain $(\beta$ - 13.05 95\%CI -22.62,-3.47), lower score on the DN4 for neuropathic pain ( $\beta 15.2795 \% \mathrm{CI} 6.75,23.78$ ), lower BMI ( $\beta 1.2595 \%$ CI $0.53,1.98$ ), lower baseline FFI score $(\beta .6395 \%$ CI $0.43,0.84)$ and lower baseline first step pain score $(\beta 2.0495 \%$ CI $0.30,3.78)$ were significantly associated with lower total FFI score at 26 weeks, indicating better outcomes. In the multivariable analysis, only female sex $(\beta-9.5995 \% \mathrm{CI}$ $17.87 ;-1.31)$ and the baseline FFI score $(\beta .5695 \% \mathrm{CI}$ $0.30,0.82)$ were associated with lower FFI total scores at 26 weeks $\left(R^{2}=0.543\right)$.

Exploratory analyses in patients treated with insoles showed no significant interaction effects between the allocated treatment (custom-made versus sham) and any of the potential predictive factors (Table 4).

\section{Discussion}

All three treatment groups showed improvement over time when compared to baseline, according to the FFI total score, recovery rate and first step pain. Women reported higher symptom and disability scores than men at baseline. Of 16 potential characteristics analyzed in this study, female sex as well as less severe symptoms at baseline were associated to better outcomes at 26 weeks follow-up in patient with PHP being treated with insoles. Of the six characteristics tested for interaction with type of treatment, none had a significant interaction. Although sex had no significant interaction with treatment effect, the confidence interval was wide and included more values on the negative side $(95 \% \mathrm{CI}-29.46 ; 5.25)$. Given the small sample size and the exploratory nature of the present analysis, it is possible this study lacked power to demonstrate interaction effects.

The FFI total score at 26 weeks was chosen as primary outcome because of its clinical relevance and the fact that a high percentage of patients improved by at least 6.5 points (the minimal important difference) at 26

Table 1 Baseline demographics $(N=185)$

\begin{tabular}{|c|c|c|c|}
\hline & $\begin{array}{l}\text { Total population } \\
N=139 \\
\text { mean (SD) unless } \\
\text { otherwise indicated }\end{array}$ & $\begin{array}{l}\text { Sham insole group } \\
N=69 \\
\text { mean (SD) unless } \\
\text { otherwise indicated }\end{array}$ & $\begin{array}{l}\text { Custom made insole } \\
\text { group } \\
N=70 \\
\text { mean (SD) unless } \\
\text { otherwise indicated }\end{array}$ \\
\hline Age, y & $48.1(10.4)$ & $48.2(9.4)$ & $48.0(11.3)$ \\
\hline Sex, female, N (\%) & $96(69.1)$ & $48(69.6)$ & $48(68.6)$ \\
\hline $\mathrm{BMI}, \mathrm{kg} / \mathrm{m}^{2}$ & $29.3(5.3)$ & $29.5(4.8)$ & $29.2(5.8)$ \\
\hline \multicolumn{4}{|l|}{ Pain history } \\
\hline FFI total score $(0-100)$ & $48.2(18.1)$ & $46.1(17.2)$ & $50.2(18.8)$ \\
\hline FFI pain score (0-100) & $57.8(17.0)$ & $55.6(17.2)$ & $60.0(16.7)$ \\
\hline FFI disability score $(0-100)$ & $39.5(21.5)$ & $37.3(19.7)$ & $41.6(23.1)$ \\
\hline First step pain score $(0-10)$ & $7.2(2.2)$ & $7.3(2.1)$ & $7.2(2.4)$ \\
\hline Pain at other sites than the affected foot, N (\%) & $61(43.9)$ & $32.0(46.4)$ & $29.0(41.4)$ \\
\hline DN4 score $(0-10)$ & $3.8(2.0)$ & $3.6(1.8)$ & $3.9(2.1)$ \\
\hline Localization of complaints, bilateral, N (\%) & $32(23.0)$ & $16(23.2)$ & $16(22.9)$ \\
\hline Duration of symptoms, months & $6.4(11.6)$ & $5.1(5.2)$ & $7.7(15.5)$ \\
\hline \multicolumn{4}{|l|}{ Activity } \\
\hline Squash questionnaire $0-\infty$ & $7751,1(5246.0)$ & $8755.3(5747.8)$ & $6761.3(4525.5)$ \\
\hline \multicolumn{4}{|l|}{ Podiatrist measurements } \\
\hline Upper ankle dorsal flexion range of motion (degrees) & $16.42(1.43)$ & $15.52(2.24)$ & $17.34(1.77)$ \\
\hline MTP1 dorsal flexion range of motion (degrees) & $61.38(2.09)$ & $61.11(3.10)$ & $61.65(2.83)$ \\
\hline $\begin{array}{l}\text { Pronated foot posture in the affected foot according to } \\
\text { the foot posture index, } \mathrm{N}(\%)\end{array}$ & $39(28.1)$ & $26(37.7)$ & $13(18.6)$ \\
\hline $\begin{array}{l}\text { Supinated foot posture in the affected foot according to } \\
\text { the foot posture index, } \mathrm{N}(\%)\end{array}$ & $14(10.1)$ & $7(10.1)$ & $7(10.0)$ \\
\hline
\end{tabular}


Table 2 Outcomes at 12 weeks and 26 weeks follow-up

\begin{tabular}{|c|c|c|c|c|c|c|}
\hline & \multicolumn{3}{|c|}{ Follow-up at 12 weeks } & \multicolumn{3}{|c|}{ Follow-up at 26 weeks } \\
\hline & $\begin{array}{l}\text { Sham insole } \\
\text { group } \\
n=68 \\
\text { mean (SD) unless } \\
\text { otherwise } \\
\text { indicated }\end{array}$ & $\begin{array}{l}\text { Custom made } \\
\text { insole group } \\
n=66 \\
\text { mean (SD) unless } \\
\text { otherwise } \\
\text { indicated }\end{array}$ & $\begin{array}{l}\text { Usual care group } \\
N=39 \\
\text { mean (SD) unless } \\
\text { otherwise } \\
\text { indicated }\end{array}$ & $\begin{array}{l}\text { Sham insole } \\
\text { group } \\
n=68 \\
\text { mean (SD) unless } \\
\text { otherwise } \\
\text { indicated }\end{array}$ & $\begin{array}{l}\text { Custom made } \\
\text { insole group } \\
n=66 \\
\text { mean (SD) unless } \\
\text { otherwise } \\
\text { indicated }\end{array}$ & $\begin{array}{l}\text { Usual care group } \\
N=38 \\
\text { mean (SD) unless } \\
\text { otherwise } \\
\text { indicated }\end{array}$ \\
\hline $\begin{array}{l}\text { FFl total score, } \\
\text { 0-100 }\end{array}$ & $30.3(21.0)$ & $30.8(23.2)$ & $30.2(24.6)$ & $24.6(24.1)$ & $25.0(23.1)$ & $22.2(26.5)$ \\
\hline $\begin{array}{l}\text { FFl total MID*, N } \\
(\%)\end{array}$ & $48(70.6)$ & $45(68.2)$ & $27(69.2)$ & $53(77.9)$ & $53(80.3)$ & $30(78.9)$ \\
\hline $\begin{array}{l}\text { Recovered**, } \\
\text { N (\%) }\end{array}$ & $25(36.8)$ & $24(36.4)$ & $15(32.6)$ & $39(57.4)$ & $35(53.0)$ & $21(55.3)$ \\
\hline $\begin{array}{l}\text { First step pain, } \\
0-10\end{array}$ & $5.0(3.0)$ & $5.0(3.0)$ & $4.0(0.0)$ & $3.0(3.0)$ & $4.0(4.0)$ & $3.0(3.0)$ \\
\hline $\begin{array}{l}\text { First step pain } \\
\text { MID, N (\%)*** }\end{array}$ & $38(55.9)$ & $39(59.1)$ & $23.0(59.0)$ & $48(70.6)$ & $43(65.2)$ & $28(73.7)$ \\
\hline
\end{tabular}

\footnotetext{
* A patient was considered to have reached a minimal important improvement in FFI if their FFI total score at follow-up was at least 6.5 (the minimal important difference) lower than at baseline

${ }^{*}$ A patient is defined as recovered if they answered 'the complaints have completely disappeared or they are strongly improved'

***A patient was considered to have reached a minimal important improvement in first step pain if their first step pain score follow-up was at least 1.9 (the minimal

important difference) lower (improved) than at baseline
}

weeks when compared to baseline. The choice for this outcome may have influenced the prognostic variables. In this study the FFI total score improved significantly in both treatment groups. At 26 weeks, $79.1 \%$ of all participants reached FFI total score MID, while $55.2 \%$ selfreported to be recovered. In literature, recovery rates of 80 to $90 \%$ within 10 to 12 months are reported [32].
Follow-up in our study was relatively short at 6 months, which may explain the lower recovery rate when compared to literature. It can be noted that many patients, regardless of a meaningful improved in function, still do not consider themselves recovered.

A high BMI is a known risk factor for the development of PHP and has been found as a prognostic factor for

Table 3 Linear regression analyses of factors associated with FFI total score at 26 weeks follow-up

\begin{tabular}{|c|c|c|c|}
\hline \multirow[b]{3}{*}{ Variables } & \multicolumn{2}{|c|}{ Patients treated with insoles (custom + sham) } & \\
\hline & \multirow{2}{*}{$\begin{array}{l}\text { Univariate } \\
\text { Unstandardized } \beta(95 \% \mathrm{Cl})\end{array}$} & \multicolumn{2}{|l|}{ Multivariable model } \\
\hline & & Unstandardized $\beta(95 \% \mathrm{Cl})$ & Standardized Beta \\
\hline Body Mass Index $\left(\mathrm{kg} / \mathrm{m}^{2}\right)$ & $1.25(0.53,1.98)^{*}$ & $0.69(-0.05,1.43)$ & 0.16 \\
\hline Comorbidities (present) & $-3.43(-13.67,6.81)$ & $-3.86(-13.87,6.15)$ & -0.06 \\
\hline Sex (female) & $-0.38(-9.05,8.29)$ & $-9.59(-17.87,-1.31)^{*}$ & 0.19 \\
\hline Age (years) & $0.08(-0.32,0,47)$ & $0.27(-0.13,0.67)$ & 0.12 \\
\hline Bilateral pain (no) & $-13.05(-22.62,-3.47)^{*}$ & $-8.41(-18.31,1.50)$ & 0.15 \\
\hline Neuropathic pain DN4 total score (0-10) & $15.27(6.75,23.78)^{*}$ & $-0.21(-2.34,1.92)$ & -0.02 \\
\hline Upper ankle joint dorsal range of motion (degrees) & $-0.10(-0.37,0.16)$ & $0.02(-0.25,0.28)$ & 0.01 \\
\hline Metatarsal phalangeal joint dorsal range of motion (degrees) & $0.06(-0.13,0,24)$ & $0.08(-0.08,0.24)$ & 0.08 \\
\hline Navicular drop (millimeter) & $-4.73(-14.74,5.29)$ & $-3.62(-13.12,5.87)$ & -0.07 \\
\hline Activity score (SQUASH) & $0.0(0.00,0.00)$ & $0.00(0.00,0.00)$ & 0.10 \\
\hline Treatment group (custom insole) & $0.36(-7.64,8.35)$ & $0.59(-7.11,8.30)$ & 0.01 \\
\hline Baseline FFI total score (0-100) & $0.63(0.43,0.84)^{*}$ & $0.56(0.30,0.82)^{*}$ & 0.43 \\
\hline Baseline first step pain (0-10) & $2.04(0.30,3.78)^{*}$ & $-0.01(-1.89,1.70)$ & -0.01 \\
\hline Duration of symptoms (months) & $0.25(-0.09,0.59)$ & $0.05(-0.30,0.40)$ & 0.02 \\
\hline Foot posture index (supination) & $0.05(-13.45,13.55)$ & $-1.14(-13.68,11.39)$ & -0.02 \\
\hline Foot posture index (pronation) & $5.07(-3.79,13.93)$ & $1.32(-7.35,10.00)$ & 0.03 \\
\hline
\end{tabular}

* $p$-value $<0.05$

In the patients treated with usual care only variables that gave a significant result in the patients treated with insoles were analyzed 
Table 4 Interaction between variables of interest and treatment with custom insoles compared to sham insoles for the total FFI score at 26-weeks follow-up

\begin{tabular}{|c|c|c|}
\hline Variables & $\begin{array}{l}\text { Unstandardized } \beta \\
(95 \% \mathrm{Cl})\end{array}$ & Interpretation \\
\hline Body Mass Index (kg/m²) & $0.49(-1.00,1.98)$ & $\begin{array}{l}\text { Lower BMl is associated with a lower total FFI score in patients treated with custom insole (non- } \\
\text { significant)** }\end{array}$ \\
\hline $\begin{array}{l}\text { Neuropathic pain DN4 } \\
\text { total score }(0-10)\end{array}$ & $1.58(-2.56,5.73)$ & $\begin{array}{l}\text { Lower score on the DN4 score for neuropathic pain is associated with a lower total FFI score in } \\
\text { patients treated with custom insole (non-significant)** }\end{array}$ \\
\hline Bilateral pain (yes) & $\begin{array}{l}-2.16(-21.49 \\
17.16)\end{array}$ & $\begin{array}{l}\text { Presence of bilateral pain is associated with a lower total FFI score in patients treated with custom } \\
\text { insole (non-significant)** }\end{array}$ \\
\hline Sex (male) & $\begin{array}{l}-12.10(-29.46, \\
5.25)\end{array}$ & $\begin{array}{l}\text { Male sex is associated with a with a lower total FFI score in patients treated with custom insole } \\
\text { (non-significant)** }\end{array}$ \\
\hline FFI score at baseline & $0.02(-0.39,0.43)$ & $\begin{array}{l}\text { Lower FFI score at baseline is associated with a lower total FFI score in patients treated with } \\
\text { custom insole (non-significant)** }\end{array}$ \\
\hline First step pain at baseline & $0.47(-3.07,4.01)$ & $\begin{array}{l}\text { Lower pain score for first step pain at baseline is associated with a lower total FFI score in patients } \\
\text { treated with custom insole (non-significant) }{ }^{* *}\end{array}$ \\
\hline
\end{tabular}

*Variables were multiplied with a factor indicating treatment (custom insole vs sham)

**A lower total FFI is indicative of a lower pain and better function

long lasting complaints in patients treated with insoles in a previous study $[5,18,33]$. In the present study there was no significant association between BMI and the total FFI score in the multivariable model. However, BMI was associated with the FFI score in the univariate model. This is likely due to the relatively lower (better) FFI scores at baseline in those with a relatively low BMI and therefore only the FFI score at baseline remained significant in the multivariable model.

PHP is more common among females, however the relationship between sex and prognosis was still unknown [3]. In the present study, both sexes showed general improvement of symptoms, as is expected in a self-limiting disease. Women reported higher symptom and disability scores than men at baseline, but reported similar scores to males at 26 weeks. In the present study sex went from being non-significant in the univariate model to being significant in the multivariable model. The significance of sex changed when the baseline FFI total score was added to the model. Indicating that when the higher score reported by females at baseline (indicating higher disability) is taken into account, sex is a significant prognostic factor.

\section{Strengths and limitations}

To our knowledge, so far only one study has focused on patient characteristics that predict response to treatment with insoles in patients with PHP. A strength of this analysis is the fact that is based on a high-quality randomized trial where we found no differences between custom-made insoles and sham insoles [15]. This means that the context for patients in these two treatment groups was identical and that the data from trial is suitable to assess the prognosis and interaction of insole treatment in patients with PHP.
The main limitation of this analysis is the relatively small sample size of 139 patients. The data in the STAP study was not collected with the primary aim to perform these analyses. This limited the power and the number of potential patient characteristics that could be included. Some confidence intervals were wide and further analysis with higher power may potentially identify significant effects. Moreover, the explained variance of the multivariable model was rather low, with an explained variance of $54 \%$.

There are no studies on prognostic variables for PHP in populations with another treatment than insoles, it therefore remains unknown, whether the prognostic variables found in this study are representative in a different context.

Furthermore, PHP is a condition that can remain symptomatic for over a year in a small percentage of patients [34]. Our follow-up was limited to 26 weeks, not allowing to measure effects on the longer term. Also, 32 participants with bilateral foot complaints were randomized into a 'left side' and 'right side' group, since data on the MTP range of motion and the navicular drop were only included of the (most) affected foot. The drawback is that for some participants we may have used measurements from the least symptomatic foot, while the FFI scores and self-reported recovery are reported for the most symptomatic foot, increasing chances for a type 2 error.

Finally, PHP is a broad term which can cover a range of different pathologies of heel pain. Given the inclusion criteria of the STAP-study, it is possible that the patients included in this study have a range of different causes of heel pain as we did not include the specific criteria of pain at palpation of the medial tubercle of the calcaneus. Therefore, the exact origin of the participants's complaints remains unknown. However, exploring a wide 
differential diagnosis of PHP is often not indicated, since it does not influence clinical decision making [2]. We therefore believe the population included in this study is representative for the population presenting to the GP with PHP.

\section{Conclusions}

Female sex and less severe initial complaints, in terms of foot function, are associated with lower total FFI score at 26 weeks in patients with PHP who receive treatment with insoles. Future studies should take a difference in response to treatment with insoles for males versus females into account in their design.

\section{Acknowledgements}

We thank the participants who volunteered to participate in the study and the GP's that recruited participants in their practices. Also we thank the podiatrists who were involved in the consensus meeting on the interventions and who provided the intervention to the participants.

\section{Authors' contributions}

PJB, SMA-BZ, MvM contributed to the conception and design of the study; NR, SMA-BZ and MvM contributed to the data acquisition; NR, LD performed the analysis; all contributed to interpretation of data; NR, MvM, LD drafted the work; all approved the submitted version and all have agreed both to be personally accountable for the author's own contributions and to ensure that questions related to the accuracy or integrity of any part of the work, even ones in which the author was not personally involved, are appropriately investigated, resolved, and the resolution documented in the literature.

\section{Funding}

This trial is funded by The Netherlands Organisation for Health Research and Development (ZonMW) under number: 839110008 . The Dutch Association of Podiatrist (NVvP) funded the intervention provided to patients in the insole and the sham group.

\section{Availability of data and materials}

The datasets used and/or analysed during the current study are available from the corresponding author on reasonable request.

\section{Declarations}

\section{Ethics approval and consent to participate}

The trial adhered to the principles of the Declaration of Helsinki and the medical ethical committee of the Erasmus Medical Centre has approved the study (MEC: 2015-253).

\section{Consent for publication}

Not applicable.

\section{Competing interests}

The authors declare that they have no competing interests.

Received: 23 April 2021 Accepted: 1 February 2022

Published online: 10 February 2022

\section{References}

1. Buchbinder R. Clinical practice. Plantar fasciitis N Engl J Med. 2004;350(21): 2159-66. https://doi.org/10.1056/NEJMcp032745.

2. Riel H, Cotchett M, Delahunt E, Rathleff MS, Vicenzino B, Weir A, et al. Is 'plantar heel pain' a more appropriate term than 'plantar fasciitis'? Time to move on. Br J Sports Med. 2017;51(22):1576-7. https://doi.org/10.1136/ bjsports-2017-097519.

3. Rasenberg N, Bierma-Zeinstra SM, Bindels PJ, van der Lei J, van Middelkoop M. Incidence, prevalence, and management of plantar heel pain: a retrospective cohort study in Dutch primary care. Br J Gen Pract. 2019; 69(688):e801-e8. https://doi.org/10.3399/bjgp19X706061.
4. Martin RL, Davenport TE, Reischl SF, McPoil TG, Matheson JW, Wukich DK, et al. Heel pain-plantar fasciitis: revision 2014. J Orthop Sports Phys Ther. 2014:44(11):A1-33. https://doi.org/10.2519/jospt.2014.0303.

5. van Leeuwen KD, Rogers J, Winzenberg T, van Middelkoop M. Higher body mass index is associated with plantar fasciopathy/'plantar fasciitis': systematic review and meta-analysis of various clinical and imaging risk factors. Br J Sports Med. 2016;50(16):972-81. https://doi.org/10.1136/ bjsports-2015-094695.

6. Beeson P. Plantar fasciopathy: revisiting the risk factors. Foot Ankle Surg. 2014;20(3):160-5. https://doi.org/10.1016/j.fas.2014.03.003.

7. Yildiz Kl, Misir A, Kizkapan TB, Cukurlu M. Changes in Rearfoot alignment in chronic plantar heel pain. J Foot Ankle Surg. 2018;57(3):518-20. https://doi. org/10.1053/j.jfas.2017.11.021.

8. Hansen L, Krogh TP, Ellingsen T, Bolvig L, Fredberg U. Long-term prognosis of plantar fasciitis: a 5- to 15-year follow-up study of 174 patients with ultrasound examination. Orthop J Sports Med. 2018;6(3):2325967118757983. https://doi.org/10.1177/2325967118757983.

9. DiGiovanni BF, Nawoczenski DA, Malay DP, Graci PA, Williams TT, Wilding GE, et al. Plantar fascia-specific stretching exercise improves outcomes in patients with chronic plantar fasciitis - a prospective clinical trial with twoyear follow-up. J Bone Joint Surg Am Vol. 2006;88A(8):1775-81. https://doi. org/10.2106/JBJS.E.01281

10. Irving DB, Cook JL, Young MA, Menz HB. Impact of chronic plantar heel pain on health-related quality of life. J Am Podiatr Med Assoc. 2008;98(4): 283-9. https://doi.org/10.7547/0980283.

11. Landorf KB. Plantar heel pain and plantar fasciitis. BMJ Clin Evid. 2015;2015.

12. Cornwall MW, McPoil TG. Plantar fasciitis: etiology and treatment. J Orthop Sports Phys Ther. 1999;29(12):756-60. https://doi.org/10.2519/jospt.1999.2 9.12.756.

13. Rasenberg N, Fuit L, Poppe E, Kruijsen-Terpstra AJ, Gorter KJ, Rathleff MS, et al. The STAP-study: the (cost) effectiveness of custom made orthotic insoles in the treatment for plantar fasciopathy in general practice and sports medicine: design of a randomized controlled trial. BMC Musculoskelet Disord. 2016;17(1):31. https://doi.org/10.1186/s12891-0160889-y.

14. Whittaker GA, Munteanu SE, Menz HB, Tan JM, Rabusin CL, Landorf KB. Foot orthoses for plantar heel pain: a systematic review and meta-analysis. $\mathrm{Br} J$ Sports Med. 2018;52(5):322-8. https://doi.org/10.1136/bjsports-2016-097355.

15. Rasenberg N, Bierma-Zeinstra SMA, Fuit L, Rathleff MS, Dieker A, van Veldhoven $\mathrm{P}$, et al. Custom insoles versus sham and GP-led usual care in patients with plantar heel pain: results of the STAP-study - a randomised controlled trial. Br J Sports Med. 2021;55(5):272-8. https://doi.org/10.1136/ bjsports-2019-101409.

16. Rasenberg N, Riel H, Rathleff MS, Bierma-Zeinstra SMA, van Middelkoop M. Efficacy of foot orthoses for the treatment of plantar heel pain: a systematic review and meta-analysis. Br J Sports Med. 2018;52(16):1040-6. https://doi. org/10.1136/bjsports-2017-097892.

17. Morrissey D, Cotchett M, Said J'Bari A, Prior T, Griffiths IB, Rathleff MS, et al. Management of plantar heel pain: a best practice guide informed by a systematic review, expert clinical reasoning and patient values. Br I Sports Med. 2021;55(19):1106-18. https://doi.org/10.1136/bjsports-2019-101970.

18. Whittaker GA, Landorf KB, Munteanu SE, Menz HB. Predictors of response to foot orthoses and corticosteroid injection for plantar heel pain. J Foot Ankle Res. 2020;13(1):60. https://doi.org/10.1186/s13047-020-00428-6.

19. Wu FL, Shih YF, Lee SH, Luo HJ, Wang WT. Can short-term effectiveness of anti-pronation taping predict the long-term outcomes of customized foot orthoses: developing predictors to identify characteristics of patients with plantar heel pain likely to benefit from customized foot orthoses. BMC Musculoskelet Disord. 2019;20(1):264. https://doi.org/10.11 86/s12891-019-2648-3.

20. World Medical A. World medical association declaration of Helsinki: ethical principles for medical research involving human subjects. JAMA. 2013; 310(20):2191-4. https://doi.org/10.1001/jama.2013.281053.

21. van Seventer R, Vos C, Giezeman M, Meerding WJ, Arnould B, Regnault A, et al. Validation of the Dutch version of the DN4 diagnostic questionnaire for neuropathic pain. Pain Pract. 2013;13(5):390-8. https://doi.org/10.1111/pa pr.12006.

22. Kuyvenhoven MM, Gorter KJ, Zuithoff P, Budiman-Mak E, Conrad KJ, Post MW. The foot function index with verbal rating scales (FFI-5pt): a clinimetric evaluation and comparison with the original FFI. J Rheumatol. 2002;29(5): 1023-8. 
23. Wendel-Vos GC, Schuit AJ, Saris WH, Kromhout D. Reproducibility and relative validity of the short questionnaire to assess health-enhancing physical activity. J Clin Epidemiol. 2003;56(12):1163-9. https://doi.org/10.101 6/50895-4356(03)00220-8.

24. Brody DM. Techniques in the evaluation and treatment of the injured runner. Orthop Clin North Am. 1982;13(3):541-58. https://doi.org/10.1016/ S0030-5898(20)30252-2.

25. Redmond AC, Crosbie J, Ouvrier RA. Development and validation of a novel rating system for scoring standing foot posture: the Foot Posture Index. Clin Biomech (Bristol, Avon). 2006;21(1):89-98.

26. Landorf KB, Radford JA. Minimal important difference: values for the foot health status questionnaire, foot function index and visual analogue scale. Foot. 2008;18(1):15-9. https://doi.org/10.1016/j.foot.2007.06.006.

27. Landorf KB, Radford JA, Hudson S. Minimal important difference (MID) of two commonly used outcome measures for foot problems. J Foot Ankle Res. 2010;3(1):7. https://doi.org/10.1186/1757-1146-3-7.

28. van Leeuwen KD, Rogers J, Winzenberg T, van Middelkoop M. Higher body mass index is associated with plantar fasciopathy/'plantar fasciitis': systematic review and meta-analysis of various clinical and imaging risk factors. Br J Sports Med. 2015;50(16):972-81. https://doi.org/10.1136/ bjsports-2015-094695.

29. Aranda Y, Munuera PV. Plantar fasciitis and its relationship with hallux limitus. J Am Podiatr Med Assoc. 2014;104(3):263-8. https://doi.org/10.7547/ 0003-0538-104.3.263.

30. Ribeiro AP, Sacco IC, Dinato RC, Joao SM. Relationships between static foot alignment and dynamic plantar loads in runners with acute and chronic stages of plantar fasciitis: a cross-sectional study. Braz J Phys Ther. 2016; 20(1):87-95. https://doi.org/10.1590/bjpt-rbf.2014.0136.

31. White IR, Royston P, Wood AM. Multiple imputation using chained equations: issues and guidance for practice. Stat Med. 2011;30(4):377-99. https://doi.org/10.1002/sim.4067.

32. League AC. Current concepts review: plantar fasciitis. Foot Ankle Int. 2008; 29(3):358-66. https://doi.org/10.3113/FAl.2008.0358.

33. Rano JA, Fallat LM, Savoy-Moore RT. Correlation of heel pain with body mass index and other characteristics of heel pain. J Foot Ankle Surg. 2001; 40(6):351-6. https://doi.org/10.1016/S1067-2516(01)80002-8.

34. Digiovanni BF, Nawoczenski DA, Malay DP, Graci PA, Williams TT, Wilding $G E$, et al. Plantar fascia-specific stretching exercise improves outcomes in patients with chronic plantar fasciitis. A prospective clinical trial with twoyear follow-up. J Bone Joint Surg Am. 2006;88(8):1775-81. https://doi.org/1 0.2106/00004623-200608000-00013.

\section{Publisher's Note}

Springer Nature remains neutral with regard to jurisdictional claims in published maps and institutional affiliations.

Ready to submit your research? Choose BMC and benefit from:

- fast, convenient online submission

- thorough peer review by experienced researchers in your field

- rapid publication on acceptance

- support for research data, including large and complex data types

- gold Open Access which fosters wider collaboration and increased citations

- maximum visibility for your research: over $100 \mathrm{M}$ website views per year

At BMC, research is always in progress.

Learn more biomedcentral.com/submissions 